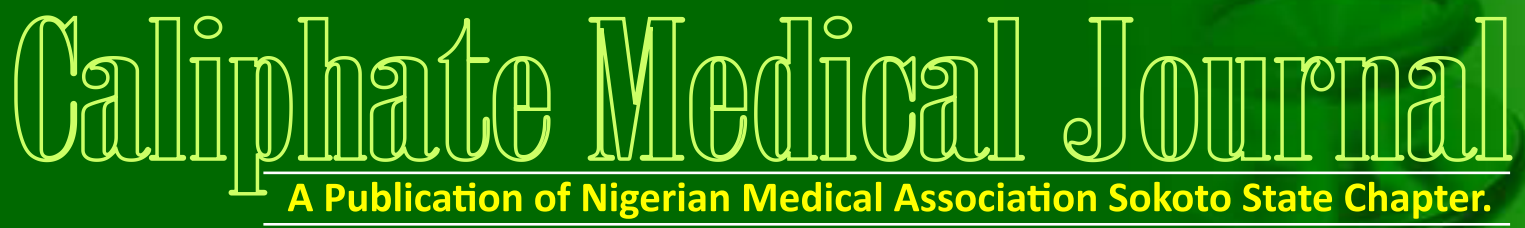

Vol 9, No. 2, April - June, 2021

ISSN: 2346

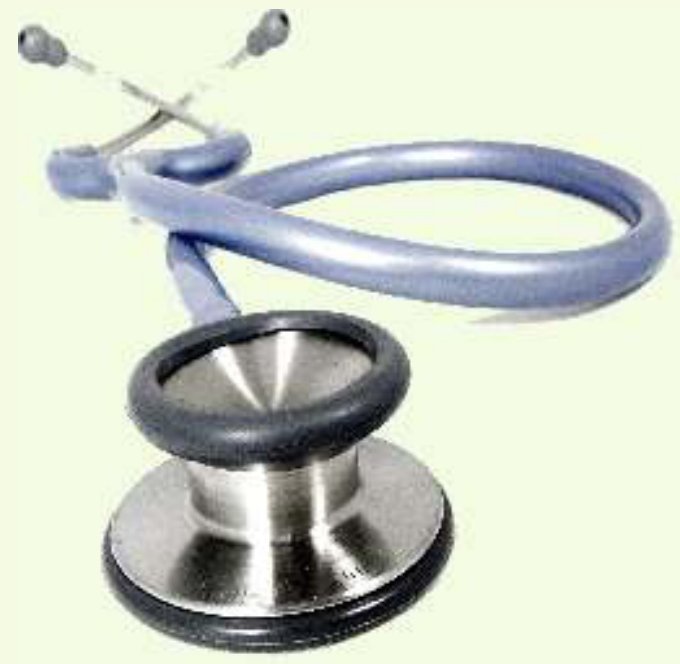

In this Issue
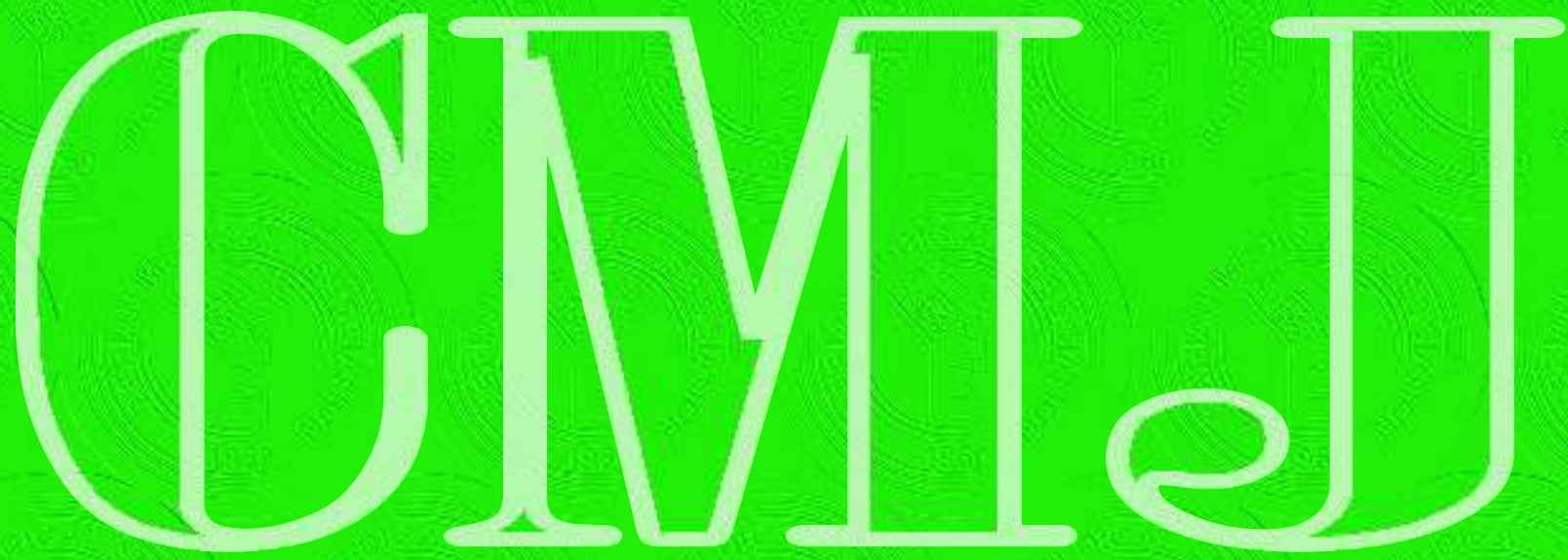


\title{
HUMAN PAPILLOMAVIRUS ONCOGENESIS: A NARRATIVE REVIEW
}

\author{
Hudu, $\mathrm{SA}^{1}$ and Aliyu, $\mathrm{UM}^{2}$
}

Department of Medical Microbiology and Parasitology, Faculty of Basic Clinical Sciences,

College of Health Sciences, Usmanu Danfodiyo University, Sokoto, 840232 Sokoto State. ${ }^{2}$ Department of Radiotherapy and Oncology, Usmanu Danfodiyo University Teaching Hospital, Sokoto

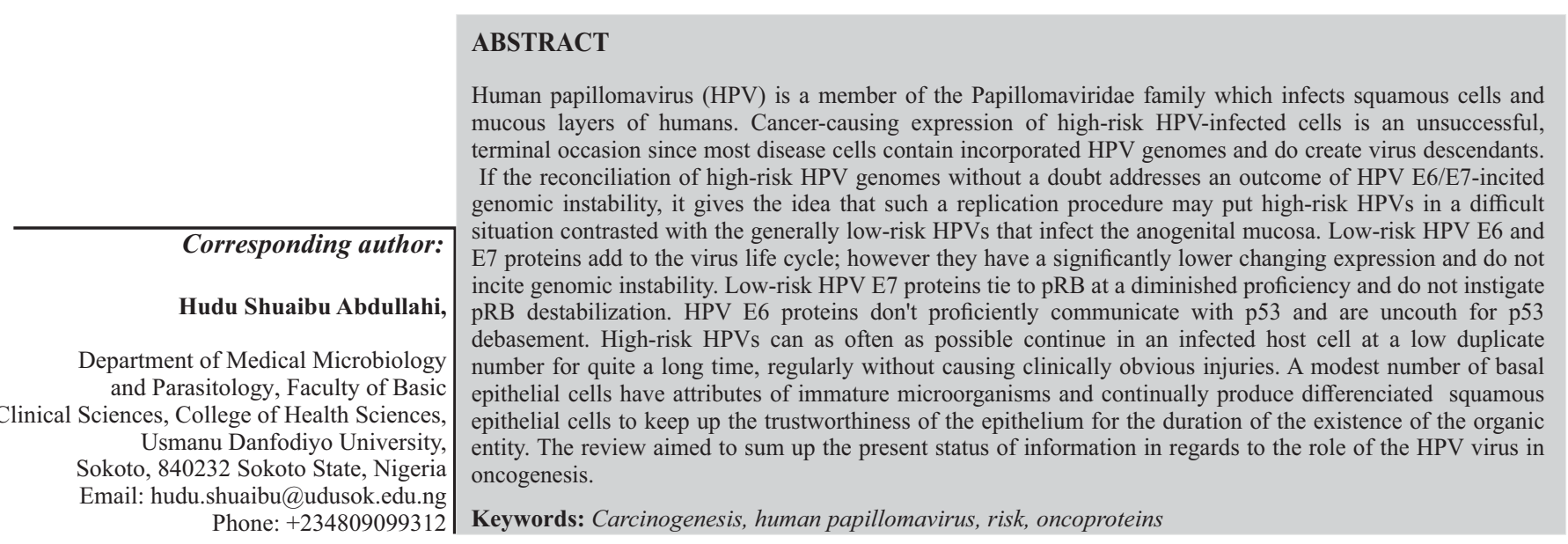

\section{Introduction}

$\mathbf{H}$ uman Papillomaviruses are a small non-enveloped virus with 55-nm-distance across icosahedral capsids that contain two-fold abandoned DNA genomes of around 8,000 bp. ${ }^{1}$ They are generally dispersed all through the set of all animals, explicitly infecting squamous epithelia, and cause the development of warts. An irresistible aetiology of warts was for quite some time suspected and in the long run, demonstrated in the nineteenth century. ${ }^{2}$ In a previous study, it was noticed that a comparable coincidental transmission of laryngeal papilloma and performed self-vaccination explores different possibilities regarding laryngeal papilloma extracts applied to scarified destinations on his lower arm, and these studies yielded warts after a long latency time of nine months. ${ }^{3}$ Comparative immunization tests had additionally been performed with extricates got from regular hand warts, and sequential vaccination experiments with human subjects were performed. ${ }^{4,5}$ Genital warts and cervical malignant growth were for quite some time viewed as appearances of then-normal venereal illnesses like syphilis and gonorrhoea. ${ }^{6}$ Speciment of a penile condyloma that was gathered from a young medical student who didn't display other clear indications of venereal illnesses were utilized to vaccinate regions on the lower arms of the creator and his partner just as the genital mucosa of a "virgo intacta." After two months, the sad female subject developed genital condyloma, and level warts showed up on the lower arms of two male probands. ${ }^{7,8}$

The possibility that a couple of wart have an inalienable propensity for malignant transformation was reported previously by reserachcers. These investigators found that sores that shaped in home-grown hares after vaccination with cottontail hare wart removes were particularly susceptible to malignant transformation. ${ }^{10}$ Cautious transmission considers showed that such speciment caused the development of warts just in hares and not indifferent animals, hence delineating the impeccable species explicitness of papillomaviruses. Gissmann and Hausen ${ }^{12}$ research facility were the first to exhibit that genital warts contain human papillomavirus (HPV) genomes following low-severity hybridization ex-pediments with HPV sequence isolated from genital warts acted in his research centre prompted the revelation of related HPV arrangements in cervical malignant growth tissues. ${ }^{13,14}$

\section{Medical Importance of Human Papillomavirus}

Roughly, 200 distinctive HPVs have now been characterized, and new sorts are consistently added to this rundown. ${ }^{15}$ This virus can be grouped into mucosal and cutaneous HPVs. Inside every one of these HPV gatherings, individual viruses are designated high risk as indicated by the penchant for threatening expression of the sores that they cause. Most HPVs are low risk and produce limited considerate warts that do not go through Malignant transformation regardless of whether they are treated or not. Among the cutaneous HPV types, HPV-5 and HPV-8 might be named high danger, as they are related to the creation of epidermodysplasia verruciformis $(\mathrm{EV})$, an incredibly uncommon skin condition that gave perhaps the most punctual sign that HPVs may add to human tumorigenesis. ${ }^{16,17} \mathrm{EV}$ patients present with level wart-like cutaneous injuries in youth and as often as possible create skin diseases further down the road, especially in sun-uncovered epithelial regions. There is an unmistakable hereditary segment to this sickness, and the expanded occurrence of EV-related tumours in safe stifled patients suggests that Malignant transformationis identified with an imperfection in immune observation. ${ }^{18,19}$ HPV-5-and HPV-8related HPVs have been distinguished in an enormous level of non-melanoma skin malignancies, especially those that create invulnerable stifled patients. It has been recommended that these viruses may likewise add to psoriasis and skin tumours in invulnerable capable people. There have been not many sub-atomic investigations with EV-type HPVs that yield experiences in regards to the sub-atomic way ways by which these viruses may add to skin cancer-causing agents. ${ }^{20-22}$

Low-risk HPV like HPV-6 and HPV-11 are associated with genital warts like condyloma acuminate, while the high-risk type is associated with a squamous intraepithelial lesion that can progress to squamous cell carcinoma. Most human cervical illnesses are identified with high-risk HPV. HPV-16 is far beyond anyone's expectations the most unavoidable mucosal high-risk HPV type, followed by HPV-18, HPV-31, 
and others. ${ }^{23}$ Oral malignant growth constitutes about 20\% of oropharyngeal carcinomas in patients that don't have the associated risk factors of tobacco and alcohol abuse. ${ }^{24}$ Additional anogenital malignancies that are identified with high-risk HPV includes penile and vulvovaginal tumours ${ }^{25}$ similarly to anal carcinomas, which sometimes occur in individuals with human immunodeficiency infection-related AIDS. ${ }^{26}$ Generally, both the high risk and the low-risk HPV matches with the changing capacity of the individual infection genomes in cell culture and transgenic mouse models. $^{21}$

Consequently, a large part of the published research has zeroed in on the investigation of the changing activities of mucosal high-risk HPVs that are related to cervical malignancy. This survey sums up these bits of facts.

\section{Genomic Make-up and Replication Cycle of Human Papillomavirus}

It is only one of the two strands of the papillomavirus round DNA genome that is adequately deciphered. The genome can be separated into three huge sections: a 4-kb early (E) locale that encodes non-underlying proteins, a 3-kb late (L) district that encodes the two capsid proteins, and a $1-\mathrm{kb}$ non-coding long control area that contains a combination of cis parts, which oversee infection replication and quality articulation. E and L qualities are numbered by size; the higher the number, the more unassuming the relating open perusing outline as displayed in Figure 1.

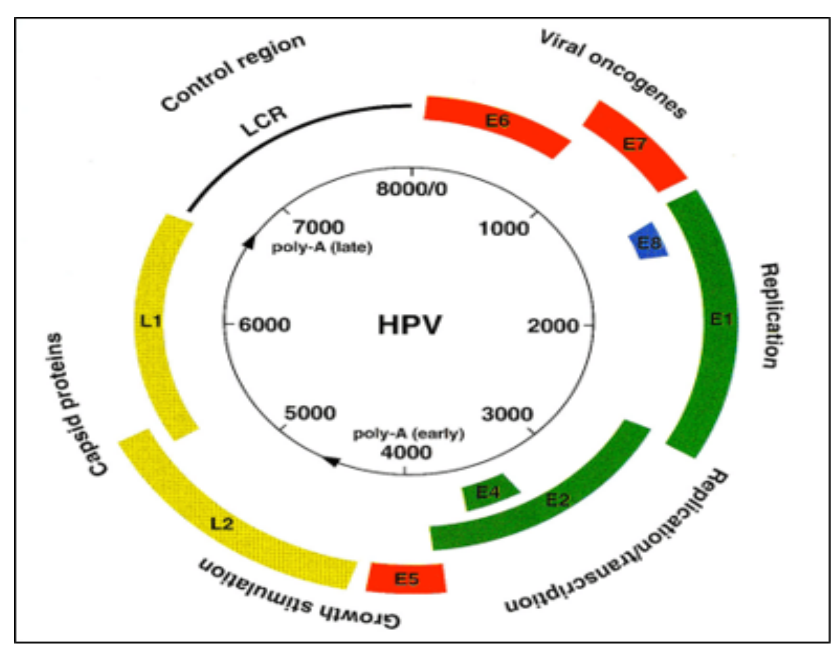

Figure 1: Schematic representation of the HPV-16 double-stranded circular DNA genome. The early (E) and late (L) genes, as well as the control region (LCR), are shown. The viral oncogenes are highlighted in red, replication proteins in green, capsid proteins in yellow. Source: Kroupis and Vourlidis. ${ }^{27}$

The HPV replication cycle is associated with the differentiation of the epithelium. The HPV at first infect basal epithelial cells, which contain only one cell layer in an epithelium that is successfully isolating. The cycle that intercedes infection take-up, de-encapsidation, and nuclear integration into the viral genome remains unclear. The HPV DNA is maintained at a low copy number in the infected host cells as they go through division and push toward the outside of the epithelium. In distanced isolated cells, the HPV replicates to a high copy number, expressing late oncogenes. ${ }^{28,29}$ HPVs are non-lytic diseases, and the relative's infection is shed into the surroundings as freight inside epithelial. The HPV oncoprotein E4 accomplices with keratin midway filaments, which impact the mechanical strength of the keratin association and may work with the appearance of infection particles. ${ }^{30}$ The papillomavirus E1 and E2 proteins assume significant parts in virus genome replication. E2 is a DNA restricting transcription factor that communicates with the ACCN6GGT motif in the virus long control region. ${ }^{31}$ High-risk HPV E2 proteins can go about as transcriptional activators, yet they work as transcriptional repressors of virus gene expression in keratinocytes. ${ }^{32,33}$

In any case, regulating infection quality articulation, HPV E2 proteins collaborate with the infection DNA helicase E1. This participation is significant for capable starting affirmation and infection genome replication. HPV E2 proteins moreover accept huge parts in infection genome disengagement during cell division by binds infection genomes to mitotic chromosomes. $^{34}$ the relationship of E2 with mitotic chromosomes is intervened by interrelating with the human bromodomain protein. ${ }^{35}$ Since HPVs don't encode various catalysts that are rate-limiting for DNA replication, the creation of infection genomes is dependent upon the host cell DNA union contraption. HPV is redeveloped in separated squamous epithelial cells that are development captured and as such naturally sad to help genome joining. From this time forward, HPVs encode limits that make or save a replicationcompetent cell milieu in contaminated segregated keratinocytes. An extra huge piece of the HPV life cycle is the foundation of long stretch infection relentlessness in squamous epithelia, where cells ceaselessly go through separation and separated cells are shed. The specific methods that high-hazard HPVs have created to block these challenges add to their oncogenic potential.

\section{Human Papillomavirus Oncogenes}

One of the critical occasions of HPV-incited carcinogenesis is the combination of the HPV genome into a host chromosome. HPV genome integration frequently happens close to basic delicate regions of the human genome yet there are no clear problem regions for reconciliation and no proof for insertional mutagenesis. ${ }^{36,37}$ Incorporation follows a more explicit example as for the HPV genome. Expression of the virus E6 and E7 genes is reliably kept up, while different bits of the virus DNA are erased or their appearance is upset. $^{38}$ The HPV E6/E7 qualities are reliably communicated, though the leftover HPV qualities are regularly erased or not interpreted after coordination. Two significant HPV RNA species are created. One record can encode full-length E6 and E7 proteins, and another arrangement of records encodes grafted E6 proteins and the full-length E7 protein. Most HPV records in cervical disease cells are grafted downstream of the E7 quality and utilize cell joining and polyadenylation signals as shown in Figure 2.

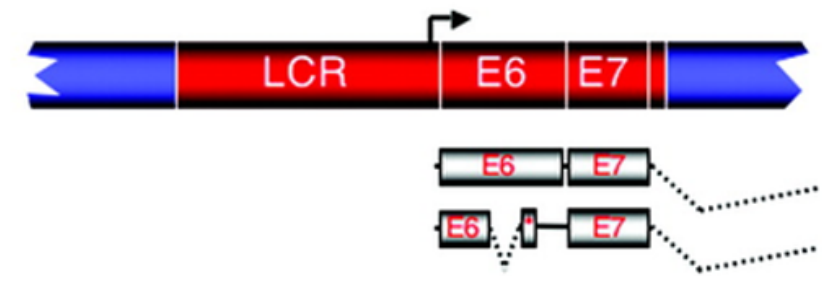

Figure 2: Schematic design of the insignificant HPV-16 genome part (red) held after incorporation into a host chromosome (blue). Source Münger, Baldwin $^{39}$ 
Failure of HPV E2 expression is very critical, as it may result in freed HPV E6 and E7 expression. There are extra reasons for extended HPV-16 E6/E7 mRNA unfaltering quality after combination, and unequivocal changes of host cell quality expression have been perceived upon HPV genomic integration. ${ }^{40,41}$ Cells expressing E6/E7 from consolidated HPV grouping have a specific advancement advantage over HPV with the episomal genome. ${ }^{42}$ The possibility that inadequacy of the E2 repressor limit may be fundamental for undermining movement is maintained by tests showing that re-expression of E2 in cervical threat cell lines causes' improvement concealment. ${ }^{43,44}$

Fusion of HPV genome into a host cell chromosome furthermore prompts insufficiency of E5 expression. In papillomaviruses that cause fibro papilloma, for instance, ox-like papillomavirus type 1, the E5 open perusing outline encodes the major changing infection protein. HPV E5 protein accomplices with intracellular layer and changes cells by activating receptor tyrosine kinases, for, not settled development factor receptor through a ligand-self-ruling framework. ${ }^{45}$ HPV E5 proteins might have tantamount exercises, and aggravation of E5 expression impacts the present example of high-hazard HPVs. ${ }^{46,47}$ The way that E5 expression isn't by and large recognized in cervical malignancies after virus genome incorporation exhibits that E5 isn't required for the support of the changed aggregate.

\section{Human Papilloma Virus Oncogenesis}

The oncogenesis of high-risk HPV E6 and E7 qualities in tissue culture and transgenic mouse model structures have been accounted for extensively. Expression of high-risk HPV E6 and E7 qualities in fundamental human keratinocytes reasonably works with their worship. ${ }^{48,49}$ High-risk HPV E6/E7 infected cells give histo-morphological indications of high-grade squamous intra-epithelial wounds, grounded precursors of cervical diseases. ${ }^{50}$ At low numbers, high-risk HPV infected cells are non-tumorigenic. They can go through ligand expression after extended advancement in tissue culture or with the expression of additional oncogenes like the fos or ras gene. ${ }^{51}$ The manifestation of cervical malignancies in a transgenic mouse model in which there is an expression of HPV-16 E6/E7 in basal epithelial cells is dependent upon long stretch receptiveness to low divides of oestrogen. ${ }^{52}$ Essentially, the expression of high-risk HPVpositive cervical lesions is regularly a lethargic cycle that happens at a low recurrence and requires the procurement of host cell transformations. ${ }^{53}$ The pace of unconstrained mutagenesis in typical human cells is really low, yet the statement of high-risk HPV E6/E7 proteins significantly expands genomic precariousness. ${ }^{54}$ Along these lines, expression of the high-risk HPV E6/E7 genes not exclusively is fundamental for the enlistment of premalignant adjustments yet additionally straightforwardly adds to harmful expression by undermining genomic dependability. ${ }^{55}$

\section{High-risk Human Papillomavirus Oncoproteins Target Cells}

A little arrangement of cell signal transduction pathways is consistently delivered useless in most human strong tumours. ${ }^{56}$ Endeavours to specify the atomic anomalies in human tumours have all the more as of late been supplemented by considers intended to characterize the smaller than expected vital arrangement of oncogenic steps important to create completely changed human epithelial cell lines in vitro. Such tests have uncovered the statement of simianvirus40 (SV40) enormous tumour antigen (T), SV40 little tumour antigen $(\mathrm{t})$, the synergist subunit of human telomerase (hTERT), and the H-ras oncogene is negligibly needed to completely change primary human epithelial cell. ${ }^{57}$ SV40 $\mathrm{T}$ practically inactivates the p53 and retinoblastoma (pRB) tumour silencers, while SV40 t associates with and represses protein phosphatase $2 \mathrm{~A} .^{58}$ The HPV E6 and E7 oncoproteins share useful similitudes with SV40 T and inactivate the $\mathrm{p} 53$ and $p R B$ tumour silencers, individually. ${ }^{59}$ Moreover, HPV E6 can actuate hTERT record. Subsequently, the statement of high-risk HPV E6/E7 oncogenes gives a subset of the minimally required cancer-causing hits for a full change of essential human epithelial cells. ${ }^{54}$

\section{Mechanism Of Human Papillomavirus Oncogenesis}

Like other oncoproteins encoded by little DNA tumour diseases, HPV collaborates with and change the elements of cell protein buildings. The amino-terminal area of HPV E7 has a collecting resemblance to a little piece of CR1 and CR2 of adenovirus E1A. The HPV E7 carboxyl end contains two copies of a CXXC topic that are secluded by a 29 -aminodestructive spacer. ${ }^{60}$ Like adenovirus E1A and SV40 T antigen, the HPV E7 proteins help out the retinoblastoma tumour silencer protein pRB and the associated "pocket proteins" p107 and p130 through an observed LXCXE gathering inside CR2 courses of action ${ }^{61,62}$ as shown in Figure 3.

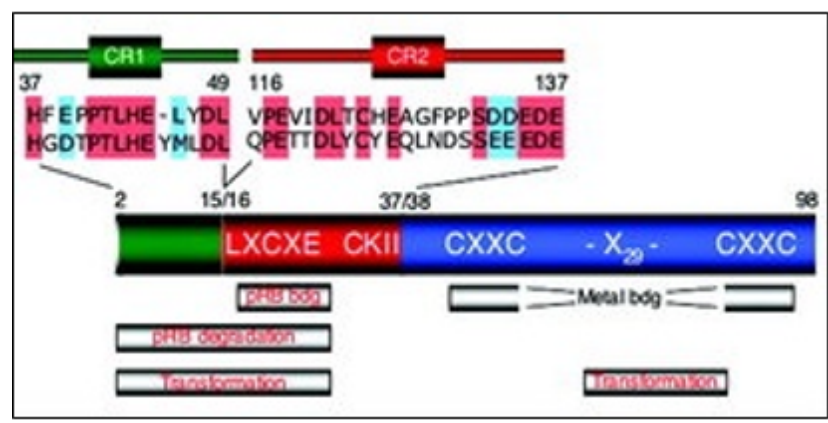

Figure 3: Showing HPV-16 oncoproteins E7 amino acids residues have sequences likeness to a piece of CR1 (green) and CR2 (red) of Ad E1A. Indistinguishable and synthetically comparable amino corrosive deposits between HPV-16 E7 and Ad5 E1A are featured by red and blue boxes, individually. The E7 carboxyl end (blue) contains a metal restricting theme and intervenes relationship with different host cell proteins, including histone-changing catalysts, which may likewise add to cell change. Source: Münger, Baldwin ${ }^{39}$

The concise proteins deal with the achievements of the E2F assembly of transcriptions factors that control various cell cycle progresses similar to other cell exercises. ${ }^{63}$ The limit of HPV E7, Ad E1A, and SV40 T antigen to associate with $\mathrm{pRB}$ is fundamental for their capacity to create just as keep a host cell milieu that is useful for infection genome replication. Consistent with this model, the change of the LxCxE area in E7 blocks the HPV life cycle. ${ }^{64} \mathrm{HPV}$ highrisk E7 proteins interface with pRB more capably than E7 proteins encoded by generally safe mucosal HPVs, and changes in the LxCxE space that impact pocket protein alliance are change flawed in different inspect systems. ${ }^{65}$ HPV E7 proteins have the clever ability to destabilize the pocket proteins through a proteasome-subordinate instrument. Regardless of the LxCxE locale, progressions inside the amino-terminal CR1 homology space of highhazard HPV E7 are central for the ability to destabilize pocket proteins. HPV E7 proteins with changes in the $\mathrm{Cr} 1$ 
homology area are in like manner change deficient. Thus, the limit of HPV E7 proteins to destabilize pocket proteins is fundamental for cell change. ${ }^{43}$

Notwithstanding pRB restricting and debasement, E7 has other cell focuses that are pertinent to cell change. HPV E7 can supersede the development inhibitory activities of cyclin-subordinate kinase inhibitors, including p21CIP $1^{66}$ and $\mathrm{p} 27 \mathrm{KIP} 1{ }^{67}$ Since these proteins are basic controllers of cell cycle capture during keratinocyte separation, their restraint by E7 may likewise add to the upkeep of a replication-capable cell milieu in isolated host epithelial cells. A carboxyl-terminal E7 region that doesn't add to pRB restricting or potentially corruption is important for the capacity of E7 to supersede p21CIP1-intervened development capture. ${ }^{68}$ Extra E7-oncoprotein, including transcription factors, cell cycle controllers, and metabolic enzymes, have been isolated by different strategies, and large numbers of these candidates seem to connect with carboxyl-terminal E7 arrangements. ${ }^{69}$ The normal importance of a considerable lot of these collaborations, be that as it may, stays to be resolved. The carboxyl-terminal HPV E7 region adds to a relationship with chromatinchanging enzymes, especially histone deacetylases and histone acetyltransferases. ${ }^{54}$ E7 has likewise been accounted for to connect with the transcriptional coactivator's p300, $\mathrm{CBP}$, and $\mathrm{pCAF}^{70}$ As the case for the amino-terminal pRB restricting site, the trustworthiness of the carboxyl-terminal E7 arrangements that have been ensnared in histone deacetylase restricting is important for the virus life cycle. ${ }^{71}$ Thus, these connections may add to changing activities of high-risk HPV E7 proteins.

\section{Conclusion}

The high-risk HPV explicit normal activities of E6 and E7 may mirror this system. Low-risk HPVs may have developed a day-to-day existence cycle that is advanced to quickly create bounteous measures of offspring virus and promptly structure enormous beneficial injuries to augment transmission of the virus to another host. Such a model may anticipate that diverse HPVs may contaminate unmistakable objective cells and that there might be contrasts in the determination of virus genomes in infected host cells.

\section{References}

1. Nguyen HP, Ramírez-Fort MK, Rady PL. The biology of human papillomaviruses. Human Papillomavirus. 2014;45:19-32.

2. Xu H, Ling Y, Xi Y, Ma H, Wang H, Hu H-M, et al. Viral metagenomics updated the prevalence of human papillomavirus types in anogenital warts. Emerg Microbes Infect. 2019;8(1):1291-9.

3. Ullmann EV. On the aetiology of the laryngeal papilloma. Acta Otolaryngol. 1923;5(4):317-34.

4. Orth G, Favre M, Croissant O. Characterization of a new type of human papillomavirus that causes skin warts. J. Virol. 1977;24(1):108-20.

5. Stehr-Green PA, Hewer P, Meekin GE, Judd LE. The aetiology and risk factors for warts among poultry processing workers. Int. $J$. Epidemiol. 1993;22(2):294-8.

6. Reid R, Stanhope CR, Herschman BR, Booth E, Phibbs GD, Smith JP. Genital warts and cervical cancer. I. Evidence of an association between subclinical papillomavirus infection and cervical malignancy. Cancer. 1982;50(2):377-87.

7. Iorga L, Marcu RD, Diaconu CC, Stanescu AMA, Stoian AP, Mischianu DLD, et al. Penile carcinoma and HPV infection. Exp. Ther. Med. . 2020;20(1):91-6.

8. Waelsch L. Übertragungsversuche mit spitzem Kondylom. Arch Dermatol Syph. 1918;124(4):625-46.

9. Kaul S, Kaur I, Jakhar D, Edigin E, Caldito EG. The diverse methods of bleomycin delivery in cutaneous warts: A literature review. Dermatol. Ther. 2021;34(1):e14401.
10. Rous P, Beard J. The progression to carcinoma of virus-induced rabbit papillomas (Shope). J. Exp. Med. 1935;62(4):523-48.

11. Rous P, Kidd JG, Beard J. Observations on the relation of the virus causing rabbit papillomas to the cancers deriving therefrom: I. The influence of the host species and the pathogenic activity and concentration of the virus. J. Exp. Med. 1936;64(3):385-400.

12. Gassmann L, Hausen HZ. Partial characterization of viral DNA from human genital warts (Condylomata acuminate). Int. J. Cancer Res. 1980;25(5):605-9.

13. Dürst M, Gissmann L, Ikenberg H, Zur Hausen H. A papillomavirus DNA from a cervical carcinoma and its prevalence in cancer biopsy samples from different geographic regions. Proc Natl Acad Sci. 1983; 80(12):3812-5.

14. Ferreira M, Gonçalves G, Sichero L. Genetic variants of HPV-16 and their geographical and anatomical distribution in men: A systematic review with meta-analysis. Virology. 2021;558:134-44.

15. Brenner N, Mentzer AJ, Hill M, Almond R, Allen N, Pawlita M, et al. Characterization of human papillomavirus (HPV) 16 E6 seropositive individuals without HPV-associated malignancies after 10 years of follow-up in the UK Biobank. EBioMedicine. 2020;62:103123.

16. Ferronika P, Sijmons RH, Febiyanto N, Radiono S, Widodo I. Acquired Human Papilloma Virus Type 6-Associated Epidermodysplasia Verruciformis in a Patient With Systemic Lupus Erythematosus. Am. J. Dermatopathol. 2020;42(11):e156-e8.

17. von Knebel Doeberitz M, Cubie H, Broker TR, Jenkins D. Linking Human Papillomavirus to Human Cancer and Understanding Its Carcinogenic Mechanisms. Human Papillomavirus. 2020. 17-39.

18. Ramoz N, Favre M, Orth G, Taïeb A, Rueda L-A, Montoya L-S, et al. Evidence for a nonallelic heterogeneity of epidermodysplasia verruciformis with two susceptibility loci mapped to chromosome regions 2p21-p24 and 17q25. J Invest Dermatol. 2000;114(6):1148-53.

19. Androphy EJ, Dvoretzky I, Lowy DR. X-linked inheritance of epidermodysplasia verruciformis: genetic and virologic studies of a kindred. Arch. Dermatol. 1985;121(7):864-8.

20. Majewski S, Jablonska S. Possible involvement of epidermodysplasia verruciformis human papillomaviruses in the immunopathogenesis of psoriasis: a proposed hypothesis. Exp Dermatol. 2003;12(6):721-8.

21. da Cruz Silva LL, de Oliveira WRP, Sotto MN. Epidermodysplasia verruciformis: revision of a model of carcinogenic disease. Surg. Exp. Pathol. 2019;2(1):1-13.

22. Chen ML, Wang SH, Wei JCC, Yip HT, Hung YM, Chang R. The Impact of Human Papillomavirus Infection on Skin Cancer: A PopulationBased Cohort Study. Oncologist. 2021;26(3):e473-e83.

23. Zur Hausen H. Papillomaviruses and cancer: from basic studies to clinical application. Nat. Rev. Cancer. 2002;2(5):342-50.

24. Sabatini ME, Chiocca S. Human papillomavirus as a driver of head and neck cancers. Br. J. Cancer. 2020;122(3):306-14.

25. Crum CP, McLachlin CM, Tate JE, Mutter GL. Pathobiology of vulvar squamous neoplasia. Curr. Opin. Obstet. Gynecol. 1997;9(1):63-70.

26. Liu Y, Sigel KM, Westra W, Gitman MR, Zheng W, Gaisa MM. HIVInfected Patients With Anal Cancer Precursors: Clinicopathological Characteristics and Human Papillomavirus Subtype Distribution. Dis Colon Rectum. 2020;63(7):890-6.

27. Kroupis C, Vourlidis N. Human papilloma virus (HPV) molecular diagnostics. Clin. Chem. Lab. Med. 2011;49(11):1783-99.

28. de Sanjose S, Brotons M, Pavon MA. The natural history of human papillomavirus infection. Best Pract Res Clin Obstet Gynaecol. 2018; 47:2-13.

29. Mamuti A, Shi Q, Lv T, Ma Z. Transient replication of human papillo mavirus type 16 in HEK293T cells. Biomed. Res 2020;31(2):37-42.

30. Saeed M, Faisal SM, Akhtar F, Ahmad S, Alreshidi MM, Kausar M, et al. Human papillomavirus induced cervical and oropharyngeal cancers: From mechanisms to potential immuno-therapeutic strategies. Curr. Drug Metab. 2020;21(3):167-77.

31. Agustiansyah P, Sanif R, Nurmaini S. Human Papilloma Virus: Bio molecular Aspect. Bioscientia Medicina: J. Biomed Trans Res. 2021; 5(3):634-41.

32. Fontan CT, Das D, Bristol ML, James CD, Wang X, Lohner H, et al. Human Papillomavirus 16 (HPV16) E2 Repression of TWIST1 Transcription Is a Potential Mediator of HPV16 Cancer Outcomes. Msphere. 2020;5(6):e00981-20.

33. Xia Y, Li J, Li S, Khodahemmati S, Ghaffar M, Chen S, et al. Identification of pathways and genes in the process of E6/E7-induced carcinogenesis of esophageal epithelial cells. J Med Virol. 2020;92(12): 3736-42.

34. Skiadopoulos MH, McBride AA. Bovine papillomavirus type 1 genomes and the E2 transactivator protein are closely associated with mitotic chromatin. J Virol. 1998;72(3):2079-88.

35. You J, Croyle JL, Nishimura A, Ozato K, Howley PM. Interaction of the bovine papillomavirus E2 protein with Brd4 tethers the viral DNA to host mitotic chromosomes. Cell. 2004;117(3):349-60.

36. Kamal M, Lameiras S, Deloger M, Morel A, Vacher S, Lecerf C, et al. 
Human papilloma virus (HPV) integration signature in Cervical Cancer: identification of MACROD2 gene as HPV hot spot integration site. Br. J. Cancer. 2021;124(4):777-85.

37. Garza-Rodríguez ML, Oyervides-Muñoz MA, Pérez-Maya AA, Sánchez-Domínguez CN, Berlanga-Garza A, Antonio-Macedo M, et al. Analysis of HPV Integrations in Mexican Pre-Tumoral Cervical Lesions Reveal Centromere-Enriched Breakpoints and Abundant Unspecific HPV Regions. Int. J. Mol. Sci. 2021;22(6):3242.

38. Rezaei M, Mostafaei S, Aghaei A, Hosseini N, Darabi H, Nouri M, et al. The association between HPV gene expression, inflammatory agents and cellular genes involved in EMT in lung cancer tissue. BMC Cancer. 2020;20(1):1-11.

39. Münger K, Baldwin A, Edwards KM, Hayakawa H, Nguyen CL, Owens $\mathrm{M}$, et al. Mechanisms of human papillomavirus-induced oncogenesis. $J$ Virol. 2004;78(21):11451-60.

40. Ren S, Gaykalova DA, Guo T, Favorov AV, Fertig EJ, Tamayo P, et al. HPV E2, E4, E5 drive alternative carcinogenic pathways in HPV positive cancers. Oncogene. 2020;39(40):6327-39.

41. Cao C, Hong P, Huang X, Lin D, Cao G, Wang L, et al. HPV-CCDC106 integration alters local chromosome architecture and hijacks an enhancer by three-dimensional genome structure remodeling in cervical cancer. J Genet Genomics. 2020;47(8):437-50.

42. McBride A, Warburton A. The role of integration in oncogenic progression of HPV-associated cancers. PLoS Pathog. 2017;13(4): e1006211.

43. Yeo-Teh NS, Ito Y, Jha S. High-risk human papillomaviral oncogenes E6 and E7 target key cellular pathways to achieve oncogenesis. Int. J. Mol. Sci. 2018;19(6):1706.

44. Thierry F, Yaniv M. The BPV1-E2 trans-acting protein can be either an activator or a repressor of the HPV18 regulatory region. EMBO Journal. 1987;6(11):3391-7.

45. DiMaio D, Mattoon D. Mechanisms of cell transformation by papillo mavirus E5 proteins. Oncogene. 2001;20(54):7866-73.

46. Chiantore MV, Mangino G, Iuliano M, Capriotti L, Di Bonito P, Fiorucci G, et al. Human Papillomavirus and carcinogenesis: Novel mechanisms of cell communication involving extracellular vesicles. Cytokine Growth Factor Rev . 2020;51:92-8.

47. Hochmann J, Parietti F, Martínez J, Lopez A, Carreño M, Quijano C, et al. Human papillomavirus type $18 \mathrm{E} 5$ oncoprotein cooperates with E6 and E7 in promoting cell viability and invasion and in modulating the cellular redox state. Mem Inst Oswaldo Cruz. 2020;115:e190405-e.

48. Hatterschide J, Brantly AC, Grace M, Munger K, White EA. A Conserved Amino Acid in the C Terminus of Human Papillomavirus E7 Mediates Binding to PTPN14 and Repression of Epithelial Differentiation. J Virol. 2020;94(17).

49. Bienkowska-Haba M, Luszczek W, Zwolinska K, Scott RS, Sapp M. Genome-wide transcriptome analysis of human papillomavirus 16infected primary keratinocytes reveals subtle perturbations mostly due to E7 protein expression. J Virol. 2020;94(3).

50. Zheng R, Heller DS. High-risk human papillomavirus identification in precancerous cervical intraepithelial lesions. J. Low. Genit. Tract Dis. 2020;24(2):197-201.

51. Pei XF, Meck JM, Greenhalgh D, Schlegel R. Cotransfection of HPV-18 and v-fos DNA induces tumorigenicity of primary human keratinocytes. Virology. 1993;196(2):855-60.

52. Kumar A, Rathi E, Hariharapura RC, Kini SG. Is viral E6 oncoprotein a viable target? A critical analysis in the context of cervical cancer. Med. Res. Rev. 2020;40(5):2019-48.
53. Yusupov A, Popovsky D, Mahmood L, Kim AS, Akman AE, Yuan H. The nonavalent vaccine: a review of high-risk HPVs and a plea to the CDC. Am. J. Stem Cells. 2019;8(3):52.

54. Songock WK, Kim S-m, Bodily JM. The human papillomavirus E7 oncoprotein is a regulator of transcription. Virus Res. 2017;231:56-75.

55. Squarzanti DF, Sorrentino R, Landini MM, Chiesa A, Pinato S, Rocchio F, et al. Human papillomavirus type 16 E6 and E7 oncoproteins interact with the nuclear p53-binding protein 1 in an in vitro reconstructed 3D epithelium: new insights for the virus-induced DNA damage response. Virol. J. 2018;15(1):1-13.

56. Schwartz L, T Supuran C, O Alfarouk K. The Warburg effect and the hallmarks of cancer. Anticancer Agents Med Chem. 2017;17(2):164-70.

57. Hahn WC, Weinberg RA. Modelling the molecular circuitry of cancer. Nat. Rev. Cancer. 2002;2(5):331-41.

58. Schuhmacher D, Sontag J-M, Sontag E. Protein phosphatase 2A: more than a passenger in the regulation of epithelial cell-cell junctions. Front. Cell Dev. Biol. 2019;7:30.

59 .Tornesello ML, Annunziata C, Tornesello AL, Buonaguro L, Buonaguro FM. Human oncoviruses and p53 tumor suppressor pathway deregulation at the origin of human cancers. Cancers. 2018;10(7):213.

60. Liu Y-H, Chen H-L, Xu B-Q, Wei K, Ying X-Y. A preliminary study on the immune responses of HPV16-E7 by combined intranasal immunization with lymphotoxin. Ginekol. Polska. 2020;91(6):301-7.

61. Rabachini T, Boccardo E, Andrade R, Perez KR, Nonogaki S, Cuccovia $\mathrm{IM}$, et al. HPV-16 E7 expression up-regulates phospholipase D activity and promotes rapamycin resistance in a pRB-dependent manner. $B M C$ Cancer. 2018;18(1):1-8.

62. Nogueira MO, Hošek T, Calçada EO, Castiglia F, Massimi P, Banks L, et al. Monitoring HPV-16 E7 phosphorylation events. Virology. 2017; 503:70-5

63. Kent LN, Leone G. The broken cycle: E2F dysfunction in cancer. Nat. Rev. Cancer. 2019;19(6):326-38.

64. Suarez I, Travé G. Structural Insights in Multifunctional Papillomavirus Oncoproteins. Viruses. 2018;10(1):37.

65. Mittal S, Banks L. Molecular mechanisms underlying human papillo mavirus E6 and E7 oncoprotein-induced cell transformation. Mutat Res Rev Mutat Res. 2017;772:23-35.

66. Shrestha S, Adhikary G, Xu W, Kandasamy S, Eckert RL. ACTL6A suppresses p21 Cip1 expression to enhance the epidermal squamous cell carcinoma phenotype. Oncogene. 2020;39(36):5855-66.

67. Bachs O, Gallastegui E, Orlando S, Bigas A, Morante-Redolat JM, Serratosa J, et al. Role of p27Kip1 as a transcriptional regulator. Oncotarget. 2018;9(40):26259.

68. Siddam AD, Gautier-Courteille C, Perez-Campos L, Anand D, Kakrana A, Dang CA, et al. The RNA-binding protein Celf1 post-transcriptionally regulates p27Kip1 and Dnase2b to control fiber cell nuclear degradation in lens development. PLoS genetics. 2018;14(3):e1007278.

69. Fischer M, Uxa S, Stanko C, Magin TM, Engeland K. Human papilloma virus E7 oncoprotein abrogates the p53-p21-DREAM pathway. Sci. Rep. 2017;7(1):1-11.

70. Huang S-M, McCance D. Down regulation of the interleukin-8 promoter by human papillomavirus type 16 E6 and E7 through effects on CREB binding protein/p300 and P/CAF. J Virol. 2002;76(17):8710-21.

71. Longworth MS, Laimins LA. The binding of histone deacetylases and the integrity of zinc finger-like motifs of the E7 protein are essential for the life cycle of human papillomavirus type 31. J Virol. 2004;78(7): $3533-41$. 